University of Nebraska - Lincoln

DigitalCommons@University of Nebraska - Lincoln

Discovery and Deployment of Molecular Markers Linked to Fusarium Head Blight Resistance: An Integrated System for Wheat and Barley

\author{
David Van Sanford \\ University of Kentucky \\ James Anderson \\ University of Minnesota \\ Kimberly A. Garland-Campbell \\ USDA-ARS, kim.garland-campbell@usda.gov \\ Josè Costa \\ University of Maryland \\ Perry Cregan \\ USDA-ARS \\ See next page for additional authors \\ Follow this and additional works at: https://digitalcommons.unl.edu/usdaarsfacpub \\ Part of the Agricultural Science Commons
}

Van Sanford, David; Anderson, James; Garland-Campbell, Kimberly A.; Costa, Josè; Cregan, Perry; Griffey, Carl; Hayes, Patrick; and Ward, Richard, "Discovery and Deployment of Molecular Markers Linked to Fusarium Head Blight Resistance: An Integrated System for Wheat and Barley" (2001). Publications from USDA-ARS / UNL Faculty. 403.

https://digitalcommons.unl.edu/usdaarsfacpub/403

This Article is brought to you for free and open access by the U.S. Department of Agriculture: Agricultural Research Service, Lincoln, Nebraska at DigitalCommons@University of Nebraska - Lincoln. It has been accepted for inclusion in Publications from USDA-ARS / UNL Faculty by an authorized administrator of DigitalCommons@University of Nebraska - Lincoln. 


\section{Authors}

David Van Sanford, James Anderson, Kimberly A. Garland-Campbell, Josè Costa, Perry Cregan, Carl Griffey, Patrick Hayes, and Richard Ward 


\title{
Discovery and Deployment of Molecular Markers Linked to Fusarium Head Blight Resistance: An Integrated System for Wheat and Barley
}

\author{
David Van Sanford,* James Anderson, Kimberly Campbell, Josè Costa, Perry Cregan, Carl Griffey, \\ Patrick Hayes, and Richard Ward
}

\begin{abstract}
Fusarium head blight (FHB), caused by Fusarium graminearum Schwabe [teleomorph Gibberella zeae (Schwein.)], is a devastating disease that reduces yield, quality and economic value of wheat (Triticum aestivum $\mathrm{L}_{\text {.) }}$ and barley (Hordeum vulgare $\mathrm{L}$.). The quantitative nature of resistance and tremendous expense of phenotypic screening indicate that the identification of resistant genotypes in breeding populations might be expedited by molecular markers. The markers must be polymorphic and informative across populations for them to be used by breeders. Worldwide, several groups are mapping genes for FHB resistance in wheat and barley and marker discovery is underway. Although these markers may be validated and made breeder-friendly by the laboratories that developed them, the urgency of the FHB situation in North America and worldwide requires efforts to accelerate this process. To take advantage of economies of scale and accelerate information sharing, we propose the establishment of a National Genotyping Center (NGC) for barley and wheat. The immediate objective of the NGC would be to identify and deploy breeder-friendly markers linked to FHB resistance quantitative trait loci (QTL). Over time, we propose that several regional genotyping centers will be established to correspond to regional and market class needs. The NGC would provide the regional centers with high throughput marker systems that would be used to genotype plants in breeding populations submitted by plant breeders. For the long term, we expect that the focus of the NGC will extend beyond FHB resistance, and that a key objective will be the development of new technologies to enhance plant breeding efforts.
\end{abstract}

$\mathrm{H}$ EAD SCAB, or Fusarium head blight of wheat and barley is a significant disease with devastating economic consequences. Losses in the USA during the 1990s approached $\$ 3000$ million (Windels, 2000). As a result, in 1997 the U.S. Wheat and Barley Scab Initiative was established. In fiscal year 1999, \$3.5 million was appropriated by Congress for research directed towards solving the problems caused by FHB (http://www.scabusa. org; verified January 15, 2001). One of the key objectives of the Scab Initiative is the rapid development of resistant cultivars. Among wheat and barley researchers in

David Van Sanford, Dep. of Agronomy, Univ. of Kentucky, Lexington, KY 40546-0091; James Anderson, Dep. of Agronomy and Plant Genetics, Univ. of Minnesota, St. Paul, MN 55108; Kimberly Campbell, USDA-ARS, Pullman, WA 99164; Josè Costa, NRSL Dep., Univ. of Maryland, College Park, MD 20742; Perry Cregan, USDA-ARS, Soybean and Alfalfa Research Lab., Beltsville, MD 20705; Carl Griffey, Dep. of Crop \& Soil Env. Sciences, Virginia Tech Univ., Blacksburg, VA 24061; Patrick Hayes, Dep. of Crop and Soil Sci., Oregon State Univ., Corvallis, OR 97331; Richard Ward, Crop and Soil Sciences Dep., Michigan State Univ., East Lansing, MI 48824. The investigation reported in this paper (00-06-75) is in connection with a project of the Kentucky Agric. Exp. Stn. and is published with the approval of the director. Received 15 April 2000. *Corresponding author (agr038@pop.uky.edu).

Published in Crop Sci. 41:638-644 (2001) the USA, the responsibility to address the challenge of rapid gene discovery and deployment falls primarily on the public sector scientists in Land Grant institutions and the USDA. Breeding programs have been provided funding to address local breeding efforts and there are coordinated germplasm screening systems in place. However, given that most programs are working with the same resistance sources and given that DNA markers for these resistance genes are emerging, a centralized laboratory that provides low cost genotyping services for major resistance QTL may speed the development of resistant cultivars.

An example of the potential utility of a centralized system can be found in two scenarios, one actual and the other hypothetical. Despite lacking complete resistance to FHB, the Chinese cultivar Sumai 3 and its derivatives are considered the most effective sources of resistance discovered so far and have been widely used in crosses (Bai and Shaner, 1994). One could argue that the first step in a rapid deployment of resistance genes should be the creation of a set of commercially viable wheat cultivars containing the Sumai 3 resistance for every market class vulnerable to FHB. While this is contrary to the conventional wisdom about genetic uniformity, all FHB-threatened farmers desire access to the best possible resistance.

In the hypothetical scenario, consider a malting barley which is resistant to the production of the FHB-induced toxin deoxynivalenol (DON), for which there is a zero tolerance in the malting industry. In recent years, malting barley production has severely declined in North Dakota and Minnesota as DON levels and yield losses reduced its comparative advantage. Growers whose livelihood depends on malting barley production would find it imperative that the resistant cultivars be available as soon as possible. Clearly, the urgency of the situation facing farmers hard hit by the disease requires a comprehensive, coordinated approach using any available technology.

One technology that could facilitate the rapid introgression of FHB resistance genes is marker-assisted (MAS) or marker-based selection (MBS). Several groups are mapping genes for FHB resistance in wheat and barley and a number of markers have been discovered (Kolb et al., 2001). These markers may be eventually validated in diverse populations and made breeder friendly by the laboratories that developed them. How-

Abbreviations: FHB, Fusarium head blight; NGC, national genotyping center; MAS, marker-assisted selection; MBS, marker-based selection QTL, quantitative trait locus; DH, doubled haploid; DON, deoxynivalenol; SSR, simple sequence repeat; SNP, single nucleotide polymorphism. 
ever, the lack of a coordinated effort to utilize markers linked to FHB resistance QTL limits our ability to deliver a nation-wide rapid response to the scenarios outlined above.

\section{Theoretical Justification for Marker-Based Selection}

Marker-assisted selection is generally thought to consist of an index of phenotypic scores and marker scores (Lande and Thompson, 1990). In practice, those breeding programs using markers linked to FHB resistance genes always follow marker genotyping with phenotype screening. In the following discussion, however, we consider selection based on marker scores alone as contrasted with selection based on phenotype alone. In evaluating the benefits of MBS for FHB resistance, one must consider the genetic correlation between the marker and the resistance QTL, and the heritabilities of the marker and FHB resistance. With estimates of heritability and genetic correlation, one we can estimate $\mathrm{Q}$, the ratio of indirect to direct selection which is expressed as the product of the genetic correlation coefficient and the ration of the square roots of the heritabilities (e.g., $Q=r_{\mathrm{g}} \times h_{1} / h_{2}$; Falconer, 1960). We used estimates of heritability of 1.0 for the marker [co-dominant marker such as simple sequence repeats (SSR)], a range from 0.3 to 0.9 for heritability of resistance, and a range from 0.1 to 0.9 for $R^{2}$, the proportion of phenotypic variation explained by the marker. In order to discuss cost effectiveness of MBS, one still needs to evaluate $\mathrm{Q}$ in terms of relative costs for direct and indirect selection. There are few estimates in the literature of the costs of scoring FHB phenotype or determining marker genotypes. Therefore, we obtained cost estimates from a subset of North American FHB researchers who had experience scoring FHB phenotype and/ or experience with molecular markers. Using estimates of $\$ 6$ per data point for resistance screening and a range from $\$ 0.50$ to $\$ 5$ per data point for SSRs, we estimated $\mathrm{Q}$ in terms of dollars spent per unit of indirect vs. direct response to selection (Fig. 1). The lowest estimate for cost per marker data point $(\$ 0.50)$ may sound unrealistic, but it is in line with low estimates reported for soybean SSR genotyping (Boerma, 2000). As one would expect, the relative cost effectiveness of MBS is greatest when the heritability of resistance is low and the genetic correlation, inferred from the $R^{2}$ estimate, is high. The range of estimates of heritability and $R^{2}$ used in this analysis include estimates found in the literature (Mari-
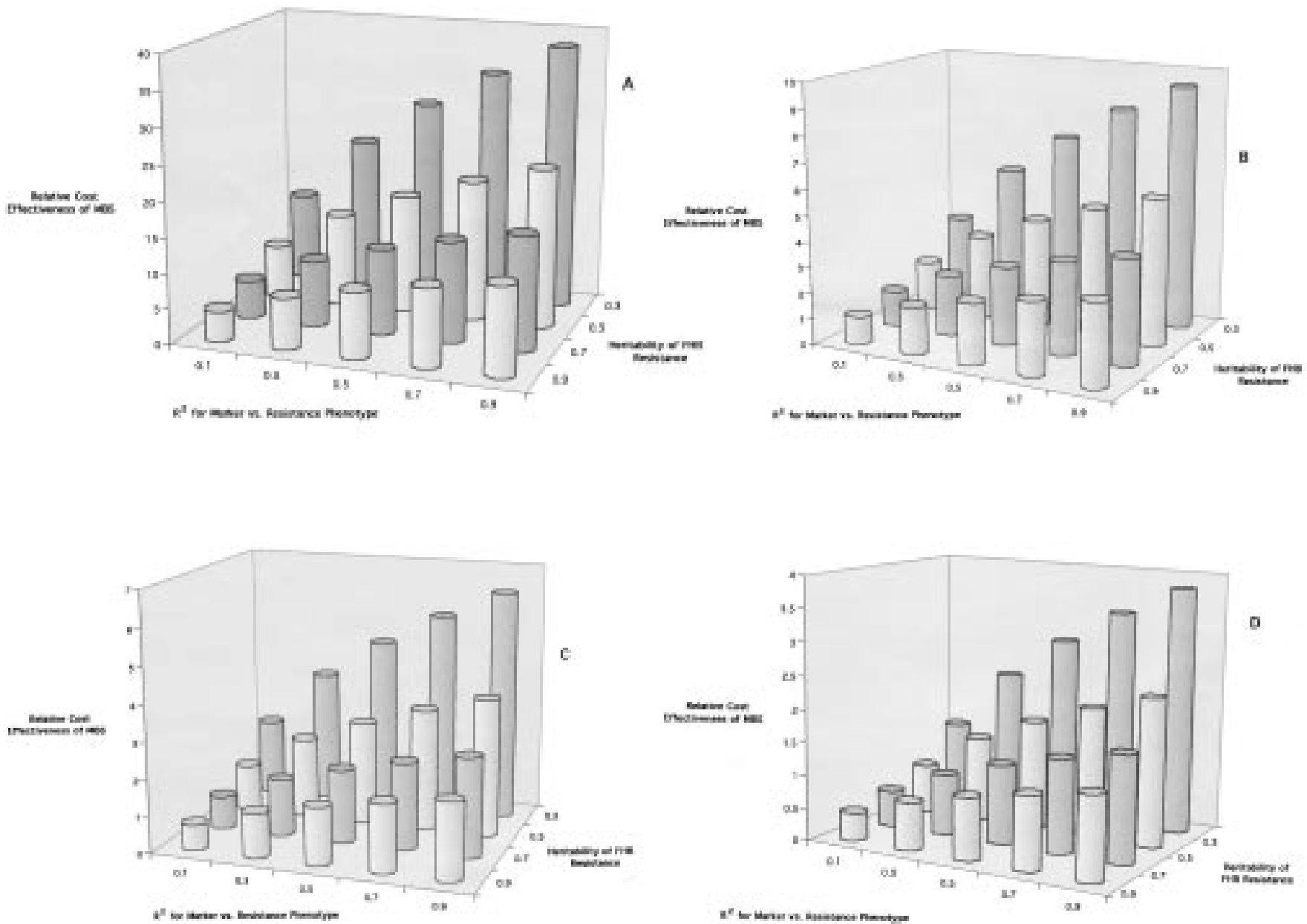

Fig. 1. Relative cost effectiveness of marker based selection (MBS) compared to selection based on resistance phenotype, given marker costs of $\$ 0.50(\mathrm{~A})$. \$2.00 (B), \$3.00 (C), and \$5.00 (D) per marker data point and a fixed cost of \$6.00 per phenotype data point. 
ana et al., 1997; Bai et al., 1999), although the upper end of each range exceeds estimates reported in the literature. For example, the highest reported $R^{2}$ value for a single marker linked to a QTL for resistance is 0.53 (Bai et al., 1999). Even when the $R^{2}$ estimate is relatively low, however, if the heritability of resistance is below 0.5, MBS should be more cost effective than selection based on phenotype alone (Fig. 1).

In the case in which "in-house" genotyping is not an option, breeders could contract MBS to a commercial lab. However, even this option might exceed the budget of most breeding programs. Using a figure of $\$ 5$ per reaction for SSR-assisted backcrossing, 300 SSRs in the initial two parent cross, and 100 SSRs to genotype 100 $\mathrm{BC} 1$ plants and 50 SSRs for $100 \mathrm{BC} 2$ plants, the cost for one population could be as high as $\$ 78000$. It is possible that this expense could be reduced by negotiating a lower cost per data point for a long-term, large scale project.

\section{Justification from a Breeder's Perspective}

Cultivar improvement predominantly has resulted from phenotypic selection wherein superior genotypes have been identified only through replicated testing in diverse environments. Plant breeders have been restricted to the use of phenotypic selection, because little is known of the genetic identity and chromosome location of most genes governing traits of importance, and few readily usable markers are available. Furthermore, little is known regarding the number and identity of the most favorable alleles governing many traits. This is particularly true for quantitative traits such as yield, for which phenotypic selection on the basis of measured performance is the only practical means of selection. Favorable alleles governing qualitative traits have been identified and incorporated into superior cultivars by both traditional and modern genetic techniques (Langridge and Chalmers, 1998). Pyramiding of resistance genes has long been a proposed method of producing genotypes with more stable and durable resistance, yet this approach has not been exploited much because of the lack of efficient selection techniques. Molecular marker technology offers the tools needed to identify, select, and combine favorable alleles via genotypic selection. Most breeding programs make hundreds to over a thousand crosses each year, and likewise advance and select among hundreds to thousands of breeding populations each year. These breeding populations are unique and represent various genetic combinations of many parental genotypes. Large numbers of populations are required for success because the identity of favorable alleles in each parent and their combining ability is unknown.

Breeding programs are accustomed to the introgression of favorable alleles for qualitative traits such as disease resistance from non-adapted germplasm into genotypes with favorable genetic backgrounds. However, this parent-building process represents only a small percentage of the total breeding effort. Genetic gain will be greatly restricted in a program that relies pre- dominantly on back crossing to incorporate favorable alleles into existing cultivars.

Given the complexity of FHB resistance, it is obvious that molecular markers could be very useful in breeding for this trait. Resistance to FHB is quantitative in nature and, while genes with major effects have been identified, none confer complete resistance. The relationships among genes controlling the five mechanisms of resistance described by Mesterhazy (1995) are not known. Molecular markers also would greatly aid in the identification and pyramiding of unique genes governing FHB resistance. Current research indicates that the level of FHB resistance conferred by single genes is not sufficient to satisfactorily reduce losses in grain yield and quality. Selective combinations of genes with additive effects or which affect different stages of the pathogenic cycle would facilitate the development of cultivars with more effective resistance.

\section{Current Limitations of MAS}

A number of markers for agronomic and grain quality traits, and biotic and abiotic stresses have been identified in wheat (Langridge and Chalmers, 1998) and barley (Hayes et al., 1996; http://www.css.orst.edu/barley/ nabgmp/qtlsum.htm; verified January 15, 2001). However, few of these are being routinely used in breeding programs (Costa, 2000), despite the observation that the "needs" of breeders are almost invariably invoked in grant proposals and publications dealing with the discovery of markers for genes in our major crop plants. The two main reasons that markers are not routinely applied in breeding programs are the (i) ineffectiveness of the markers and (ii) prohibitive cost, on a per data point basis, of using the markers in selection. The ineffectiveness of markers for simply inherited traits or for quantitative traits can result from the lack of informative polymorphism across the germplasm of interest. For QTLs, ineffectiveness often stems from issues related to genotype $\times$ environment interaction effects and the effects of different genetic backgrounds. The limitation of cost has two major components: the technical expertise and time to screen by the current markers, and the cost of screening hundreds to thousands of genotypes. Marker discovery helps to define the number of genes influencing a trait, the magnitude of their effects, and serves as a starting point for map-based cloning; however, for traits such as FHB, there is an immediate need for tools such as markers to aid in selection of resistance genes.

Because FHB resistance is quantitatively inherited, we cannot expect that the use of markers will replace conventional phenotypic screening based on greenhouse or field methods in the near future. This is because not all resistance genes are accounted for by the markers and lack of absolute linkage between the markers and genes will result in recombination and selection of susceptible genotypes. However, selection with markers prior to phenotypic screening can significantly enrich populations for resistant genotypes, thus making more efficient use of time-consuming and tedious screening 
procedures. If one accepts the hypothesis that MAS is an appropriate tool in breeding for FHB resistance, there remains the fact that the system is not in place to support its efficient implementation. Looking to the ideas of Young (1999) and Kwok and Goo (1999), it is apparent that economies of scale and rapid information sharing through bioinformatics are possible through cooperative multi-institutional efforts. For solving problems of this magnitude a "systems" approach is more appropriate than a loosely tied collection of individual efforts.

Genetic mapping of FHB resistance genes in wheat and barley is in its infancy compared to several traits in other species. Valuable lessons have been learned regarding the limitations of MAS (reviewed by Young, 1999). In addition to the reasons cited in that article, there are other issues that must be considered, some of which have to do with the culture of the scientific community in which this work is carried out. In the public sector's system that requires publication of research results for professional advancement, service functions such as the deployment of breeder-friendly markers receive scant attention. Scientists involved in mapping research do not have a compelling professional reason to devote time and resources to deploying breeder-friendly markers that can be used to meet the objectives of a mission-oriented program like the Scab Initiative. This system makes it less likely that researchers will invest the considerable time and resources required to convert the markers to a more robust form (e.g., Shan et al., 1999) that can be used by the plant breeding community. The irony of this situation is that molecular markers are still cited as having great promise as a plant breeding tool; almost every article which reports mapping data contains one or two sentences about the potential impact of the markers on plant breeding.

There is a major concern that because genotyping efforts in the private sector are dwarfing those in the public domain, there will be few markers freely available to plant breeders at public institutions (Young, 1999). Contrast this situation with the report of 10 pharmaceutical companies who recently formed the "SNP consortium" with the objective of generating a library of 300 000 single nucleotide polymorphisms and making the information public for free (Kwok and Gu, 1999). These issues come sharply into focus as we envision what might be achieved with a large-scale discovery and deployment effort targeted at FHB resistance QTLs in barley and wheat.
The questions we address in this paper are as follows.

1. Can such a system be devised?

2. What is the optimal model for a systems approach?

3. How might the near-term needs of the U.S Wheat and Barley Scab Initiative as well as the long-term needs of plant breeders be met by the implementation of such a system?

\section{National Genotyping Center}

In considering possible models, we chose to start with the concept of a national genotyping center (NGC). The components of this model would include high density molecular maps, co-dominant markers such as SSRs, high throughput characterization facilities, updated marker profiles of all parents, screening facilities, and rapid generation advance via doubled haploid technology (Penner et al., 1998). We envision that a high throughput instrument such as the 96 capillary ABI Prism 3700 DNA analyzer (Perkin-Elmer, Norwalk, CT) would be employed. This would allow for automated loading from 96 well (eventually 384 well) microtiter plates (Cregan, 1999, unpublished). On this instrument, 96 samples can be analyzed in 2 to $2.5 \mathrm{~h}(>6-8$ plates/d). With multiplexing at 10 loci, for example, one instrument could generate 8 plates $\times 96$ wells $\times 10$ loci or 7680 data points/d. The economy of scale that would be used to justify such an expensive, powerful instrument could be achieved at a multi-user facility like a NGC.

\section{NGC-The Realities of MAS in Wheat and Barley}

As markers are developed that are amenable to high throughput DNA sequence and fragment analysis (e.g., STS, SSR, and SNPs), the cost per data point should fall within the reach of breeding programs. The rationale for the establishment of a NGC for wheat and barley is to gain efficiency in DNA extraction, and facilitate the use of high-throughput marker screening equipment and procedures, and large-scale production and use of common markers. All of these efficiencies are difficult to attain in a single breeding program because the physical resources required are beyond the means of any one program. Similarly, the expense of contracted marker analysis cannot be justified for an individual program (Table 1). Because the technology and equipment is applicable to any organism, such genotyping facilities are beginning to emerge within U.S. universities and

Table 1. Time requirements for conventional vs. doubled haploid (DH) cultivar development.

\begin{tabular}{|c|c|c|c|}
\hline \multirow{4}{*}{$\begin{array}{l}\text { Timeline } \\
\text { Year } 1\end{array}$} & \multicolumn{2}{|c|}{ Conventional } & \multirow[t]{2}{*}{ Doubled haploid } \\
\hline & Spring habit & Winter habit & \\
\hline & Crossing & Crossing & Crossing \\
\hline & $\begin{array}{l}F_{1} \text {-grow-out (greenhouse) } \\
F_{2} \text { grow-out/head selection }\end{array}$ & $\mathbf{F}_{1}$-grow-out (greenhouse) & $\begin{array}{l}F_{1}-\text { Cross to Maize, } H \text {. bulbosum, } \\
\text { or begin anther culture }\end{array}$ \\
\hline Year 2 & $\begin{array}{l}F_{3} \text { Single seed descent } \\
F_{4} \text { head rows }\end{array}$ & $F_{2}$ grow-out/head selection & $F_{1}$-derived DH-grow-out \\
\hline Year 3 & $\begin{array}{l}\mathbf{F}_{4: 5} \text { Winter increase } \\
\mathbf{F}_{4: 6} \text { preliminary yield trials }\end{array}$ & $F_{3}$ head rows & $F_{3}\left(F_{1}: S_{2} \mathbf{D H s}\right)$ \\
\hline Year 4 & Replicated yield trials & $\mathbf{F}_{4}$ yield trials & $F_{4}$ yield trials \\
\hline Years 5-8 & Replicated yield trials & Replicated yield trials & Replicated yield trials \\
\hline & Reselection for purity & Reselection for purity & Reselection for purity \\
\hline Year 9 & Release & Release & Release \\
\hline
\end{tabular}


are well established in several large seed companies. Although groups of breeding programs within a university may have the resources to equip and staff a genotyping center, additional efficiencies in the production and large-scale use of probes or primers are likely to be realized in centers that handle several breeding programs of the same species.

Appropriate uses of a NGC would be for (i) mapping of populations to identify markers, (ii) development of markers amenable to high-throughput systems, (iii) routine screening of breeding lines for one or a few markers, and (iv) marker-assisted backcrossing with or without selection against the donor genome using markers. One genome-wide use of markers, marker-assisted backcrossing to select against a donor genome, with today's technology is practical only in special circumstances because of the large numbers of markers needed for analysis. In wheat, if one screens five markers per chromosome arm [approximate 20 centimorgan (cM) density], 210 polymorphic markers would be required to screen for all regions. Because of lack of polymorphism for some markers, the task of finding these appropriate 210 markers may be very difficult. Because it is a diploid, barley would require one third as many, or about 70 markers for a similar level of genome coverage, thus making genome-wide marker-assisted selection a more realistic option in this species. A more practical, immediate application of markers at a NGC may be to screen for markers that bracket the gene of interest, plus a few additional markers in other key regions as allowed by the throughput of the equipment and cost. The genomics era promises additional advances in molecular genotyping throughput and reduced cost per data point, such that a scale of analysis not possible with today's technology can be realized.

Some potential pitfalls of this plan include (i) procuring the initial funding for equipment and recurring funds for staffing, (ii) ineffectiveness of the markers, (iii) excessive cost to breeding programs, and (iv) overuse of certain markers (genes) leading to genetic vulnerability. Ineffectiveness of the markers or excessive cost would probably result in diminished participation of breeding programs. However, as the efficiency of high-throughput methods increases, costs should decline as well. The effectiveness of the markers will vary with the specific situation. The responsibility for initially developing useful markers is currently with the breeding programs and associated molecular genetic labs. The NGC could have a role in marker discovery by doing large-scale mapping using high-throughput markers, or converting existing markers to adapt to high-throughput systems. Young (1999) has noted that successful QTL mapping will depend on larger mapping populations, more replications and environments, and validation in diverse genetic backgrounds. These objectives are beyond the scope of most individual programs, but could be achieved by a NGC. The existence of a NGC is not likely to reduce the current local efforts aimed at identifying and validating markers; rather, such activities will likely be increased if there is greater promise that the resulting markers will have practical use in breeding.
The deployment of particular markers (genes) on a regional or national basis should be monitored to avoid genetic similarity and vulnerability. This is especially true for wheat-pathogen systems that exhibit gene-forgene interaction. For example, if a resistance gene and marker is found that is effective against all current races of a pathogen, there will be a strong temptation among breeders to introgress this gene if a marker is available because of its relative ease. However, widespread deployment of a single gene could lead to a quick development of virulent races. Although Fusarium species and isolates have been found to vary in aggressiveness (Snijders and Van Eeuwijk, 1991), there is no indication as yet that physiological races of the pathogen capable of overcoming the current resistance genes have emerged and resistance appears to be non specific (Van Eeuwijk et al., 1995).

\section{The Case for Doubled Haploids at a NGC}

The argument for the use of doubled haploids (DH) in wheat and barley breeding is frequently made because complete homozygosity can be achieved within one generation. In the case of spring cereals, conventional breeding and $\mathrm{DH}$ breeding programs actually require about the same amount of time from the cross to cultivar release (Table 1). For winter cereals, vernalization requirements can complicate accelerated germplasm advance under greenhouse conditions and in off-season nurseries.

The incorporation of DH breeding into a NGC will allow selection for FHB resistance to be performed more effectively. Most resistant wheat and barley germplasm is not adapted to the Eastern and North Central USA and Canada. Therefore, introgression of FHB resistance from exotic sources will require multiple generations of crossing and selection in order to develop adapted cultivars. Recurrent selection may be needed in order to concentrate FHB resistance genes from various sources into breeding populations. Utilization of markers would hasten both introgression and recurrent selection but additional mapping efforts are required in order to identify QTL linked to new sources of resistance. The use of DH breeding will create efficiencies for each of these goals.

The goal of introgression is to incorporate desired alleles from the donor with as little disturbance to the adapted parent as possible. Because $\mathrm{DH}$ production allows only one opportunity for recombination, desirable linkage blocks in the adapted parent will be maintained. For rapid introgression desired genes should be identified within one or two generations from the original cross so that better progeny can be backcrossed or top-crossed to adapted germplasm. When $n$ loci are segregating, the probability of obtaining the desired genotype in a $\mathrm{F}_{1}$-derived $\mathrm{DH}$ population is $(1 / 2)^{n}$ versus $(1 / 4)^{n}$ in an $F_{2}$ diploid population (Nei, 1963; Baenziger et al., 1984). Selection for low heritability traits such as FHB resistance is more accurate in $\mathrm{DH}$ populations than selection among $F_{2}$ plants, among $F_{2}$-derived $S_{1}$ or $\mathrm{S}_{2}$ lines, or among progeny resulting from a backcross 


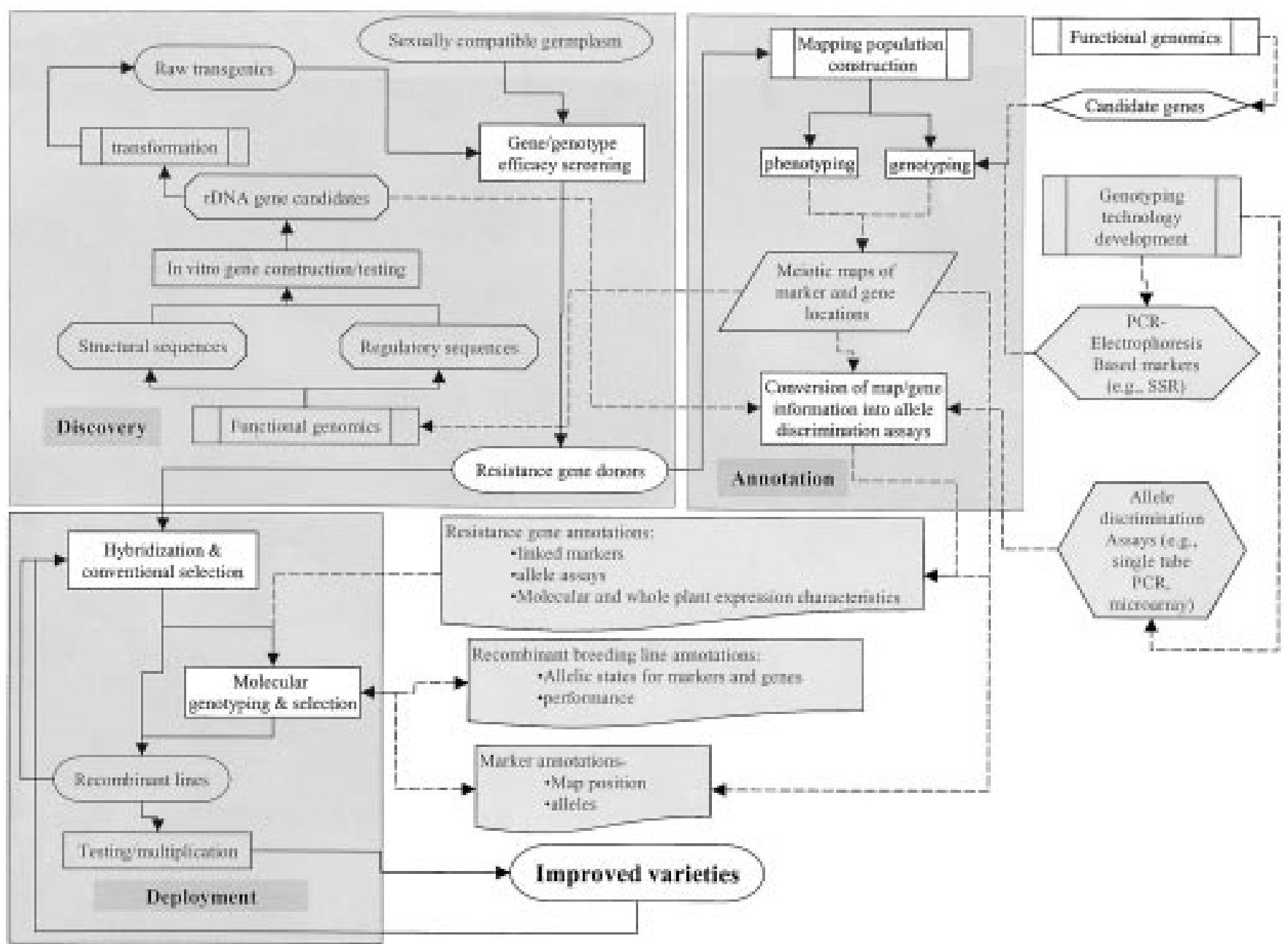

Fig. 2. Process flow diagram of gene discovery, annotation, and deployment. Boxes with lighter shading represent activities to be carried out at the National Genotyping Center.

to the adapted parent. In a DH population, narrow sense heritability is increased because additive genetic variance is twice that of a random-mated $F_{2}$ diploid population and dominance variance is absent (Griffing, 1975).

Griffing (1975) estimated the efficiency of mass selection upon individual haploid plants to be from 1.5 to 6 times more efficient than diploid mass selection, depending on the heritability and the degree of dominance affecting a trait. Although recurrent selection is not widely used in wheat and barley improvement, there is a need to accumulate as many resistance genes as possible including genes that confer different resistance mechanisms to develop a satisfactory level of FHB resistance.

The advantages of DH populations for identification of QTLs in barley, summarized by Hayes et al. (1996), also apply to the use of recombinant inbred populations developed through single seed descent (Snape, 1988). The homozygous populations can be shared among researchers so that trait evaluation and molecular marker assignment can occur in more than one location. Although recombinant inbred populations are nearly homozygous, a significant amount of heterozygosity is retained into the 5th generation of inbreeding and some care is still required to ensure that generation advance does not skew the population. In contrast, plot size in $\mathrm{DH}$ populations can be as low as one plant with certainty that the plant will breed true.

\section{NGC: Model and Implementation}

We propose that a NGC would be best operated by USDA-ARS, analogous to the existing regional wheat and barley quality labs. These quality labs were established from 1936 to 1963 and have served the industry and breeding programs well and could serve as a conceptual model. Further support for this model can be found in the Australian wheat program (Langridge and Chalmers, 1998; P. Langridge, 1999, personal communication), where individual marker labs are linked to regional breeding programs. This system allows for flexibility in dealing with different strategies and selection objectives. Furthermore, this arrangement facilitates a close alignment between breeders and mappers. Each center is staffed with a post-doctoral scientist and a technician. Two centralized staff evaluate markers in different populations, determine optimal protocols, and then send that information to the regional labs. We 
envision that the NGC would be implemented in stages. During Stage 1 an initial central lab would be established to determine the robustness of known markers linked to QTLs for FHB resistance in different populations, map diverse populations to identify new markers, genotype potential parental lines, and facilitate marker assisted backcrossing to transfer resistance QTLs into elite cultivars and lines of barley and wheat where possible. During the second phase of implementation several regional genotyping centers would be established to focus on mapping and deployment of new markers appropriate to differing regional and market class needs. Doubled haploid technology would be used to accelerate this process.

During the third stage the focus would shift to screening parents to identify polymorphic markers for new crosses, and deploying breeder-friendly gel-free markers such as molecular beacons (Tyagi et al., 1998; Cregan et al., 1999). Breeders would base initial selections on marker genotype combined with field or greenhouse screening. Selected individual plants would be advanced as DH for replicated testing. During this phase, we envision an evolution toward a centralized lab that would (i) serve primarily as the major research center for marker identification, verification, and conversion to robust, breeder friendly status, and (ii) dedicate significant resources to developing new technologies. Eventually, this lab could incorporate gene sequencing and cloning and transferring multiple genes via transformation. During this third phase, the regional centers would use high throughput marker-based systems to provide routine genotyping of plants in breeding populations that were sent from plant breeders. It is conceivable and desirable that a public-private partnership would evolve to optimize the effectiveness of the NGC (Young, 1999). If commercial plant breeders had access to the NGC, it might be possible to negotiate access to markers that were previously unavailable.

While it is important to focus on the need for genotyping and development of a rapid gene deployment system, it is clear that there are other technologies and approaches that might interface with it in a truly integrated system (Fig. 2). Our proposal is only one component of an integrated system of gene discovery, annotation and deployment.

\section{ACKNOWLEDGMENTS}

We thank Peter Langridge for his helpful comments and insight.

\section{REFERENCES}

Baenziger, P.S., D.T Kurdika, G.W. Schaeffer, M.D. Lazar. 1984. The significance of doubled haploid variation. In J.P. Gustafson (ed.) Gene manipulation in plant improvement. Plenum Publ. Co., New York, NY.

Bai, G.H., and G. Shaner. 1994. Scab of wheat: prospects for control. Plant Dis. 78:760-766.

Bai, G.H., F.L. Kolb, G. Shaner, and L.L. Domier. 1999. Amplified fragment length polymorphism in markers linked to a major quantitative trait locus controlling scab resistance in wheat. Phytopathology 89:343-348.

Boerma, H.R. 2000. Integrating DNA markers in a breeding program. http://mars.cropsoil.uga.edu/ hrb/CSSA2000/HRB.html (verified January 23, 2001).

Costa, J.M. 2000. Molecular marker assisted selection (MAS) in wheat breeding programs: Is it widespread in 1999? p. 41-43. In Proceedings of the Southern Small Grain Workers and Eastern Wheat Workers Conference, Williamsburg, VA. 2 - 4 May 1999.

Cregan, P.B., C.V. Quigley, G.N. Ude, Q. Song, and W.J. Kenworthy. 1999. Molecular beacons as a tool for single nucleotide polymorphism (SNP) detection. p. 158. In Agronomy Abstracts. ASA, Madison, WI.

Falconer, D.S. 1960. Introduction to quantitative genetics. 1st ed. Ronald Press, New York, NY.

Griffing, B., 1975. Efficiency changes due to use of doubled haploids in recurrent selection methods. Theor. Appl. Genet. 46:367-386.

Hayes, P.M., F.Q. Chen, A. Kleinhofs, A. Kilian, and D. Mather. 1996. Barley genome mapping and its applications. In P.P. Jauhar (ed.). Methods of genome analysis in plants. CRC Press, Boca Raton, FL.

Kolb, F.L., G.-H. Bai, G.J. Muehlbauer, J.A. Anderson, K.P. Smith, and G. Fedak. 2001. Host plant resistance genes for Fusarium head blight: Mapping and manipulation with molecular markers. Crop Sci. 41:611-619.

Kwok, P.Y., and Z. Gu. 1999. Single nucleotide polymorphism libraries: Why and how are we building them? Mol. Med. Today 5: 538-543.

Lande, R, and R. Thompson. 1990. Efficiency of marker-assisted selection in the improvement of quantitative traits. Genetics 124(3): $743-756$.

Langridge, P., and K. Chalmers. 1998. Techniques for marker development. p. 107-117. In A.E. Slinkard (ed.) Proc. 9th International Wheat Genetics Symposium, Saskatoon. 2-7 Aug. 1998. Univ. Extension Press, Saskatoon, SK, Canada.

Mariana, I., N.N. Saulescu, and G. Ittu. 1997. Resistance to Fusarium head blight (scab) in recombinant inbred lines derived from a Triticum aestivum cross. Cereal Res. Comm. 25:659-662.

Mesterhazy, A. 1995. Types and components of resistance to Fusarium head blight of wheat. Plant Breed. 114:377-386.

Nei, M. 1963. The efficiency of the haploid method of plant breeding. Heredity. 18:95-100.

Penner, G.A., M. Zirino, S. Kruger, and F. Townley-Smith. 1998 Accelerated recurrent parent selection in wheat with microsatellite markers. p. 131-134. In A.E. Slinkard (ed.) Proc. 9th International Wheat Genetics Symposium, Saskatoon. 2-7 Aug. 1998. Univ. Extension Press, Saskatoon, SK, Canada.

Shan, X., T.K. Blake, and L.E. Talbert. 1999. Conversion of AFLP markers to sequence-specific PCR markers in barley and wheat. Theor. Appl. Genet. 98:1072-1078.

Snape, J.W., 1988. The detection and estimation of linkage using doubled haploid or single seed descent populations. Theor. Appl. Genet. 76:125-128.

Snijders, C.H.A., and F.A. Van Eeuwijk. 1991. Genotype x strain interactions for resistnace to Fusarium head blight caused by $\mathrm{Fu}$ sarium culmorum in winter wheat. Theor. Appl. Genet. 81:239-244.

Tyagi, S., D.P. Bratu, and F.R. Kramer. 1998. Multicolor molecular beacons for allele discrimination. Nature Biotech. 16:49-53.

Van Eeuwijk, F.A., A. Mesterhazy, Ch.I. Kling, P. Ruckenbauer, L. Saur, H. Burstmayr, M. Lemmens, L.C.P. Keizer, N. Maurin, and C.H.A. Snijders. 1995. Assessing non-specificity of resistance in wheat to heed blight caused by inoculation with European strains of Fusarium culmorum, $F$. graminearum, and $F$. nivale using a multiplicative model for ineraction. Theor. Appl. Genet. 90:221228.

Windels, C.E. 2000. Economic and social impacts of Fusarium head blight: Changing farms and rural communities in Northern Great Plains. Phytopathology 90:17-21.

Young, N.D. 1999. A cautiously optimistic vision for marker-assisted breeding. Mol. Breed. 5:505-510. 